\title{
Impact of valve size, effective and indexed effective orifice area after aortic valve replacement.
}

\author{
Suvitesh Luthra ${ }^{1}$, Pietro Malvindi ${ }^{1}$, Carlo Olevano ${ }^{1}$, Anna Zingale ${ }^{1}$, Hamdi Salem ${ }^{1}$, and \\ Sunil Ohri ${ }^{1}$ \\ ${ }^{1}$ University Hospital Southampton NHS Foundation Trust
}

August 11, 2020

\begin{abstract}
Introduction - The impact of manufacturer labelled prosthesis size and predicted effective orifice area (EOA) on long term survival after aortic valve replacement is not clear although indexed effective orifice area (iEOA) has been associated with worse survival. Methods - Data was retrospectively collected from Jan 2000 - Dec 2019 for prosthesis type, model and size for isolated aortic valve replacements. Stratified survival was compared between groups and subgroups for labelled valve size, EOA and predicted PPM. Results - Total of 3444 patients were included. Moderate and severe PPM was $15.6 \%$ and $1.6 \%$ respectively. Cumulative life time hazard was worse for biological valves (mortality: biological $77.7 \%$ vs mechanical $64.8 \%$, $\mathrm{p}=0.001$ ). Mean survival was 132.7 months for biological versus 191.3 months for mechanical valves ( $\mathrm{p}=0.001$ ). Moderate prosthetic AS (EOA $=1-1.5 \mathrm{~cm} 2)$ was $12.1 \%$ and severe prosthetic AS $(\mathrm{EOA}[?] 1 \mathrm{~cm} 2)$ was $0.8 \%$ respectively. Worse survival in the presence of moderate-severe prosthetic AS was seen in biological valves (115.2 months versus 133.7 months, $\mathrm{p}=0.001$ for EOA[?]1.5cm2 and $>1.5 \mathrm{~cm} 2$ respectively). There was a statistically significant correlation between survival and iEOA (Spearman's rho=0.084, $\mathrm{p}=0.001, \mathrm{BCa}$ bootstrap 95\% CI;0.050, 0.120). Moderate to severe PPM (iEOA[?]0.85 $\mathrm{cm} 2 / \mathrm{m} 2$ ) was a predictor of worse long term survival (HR 3.56; 95\% CI: 1.37 - 9.25; $\mathrm{p}=0.009$ ). Conclusion - Predicted prosthetic moderate to severe AS and moderate to severe PPM adversely affect long term survival. Smaller valves are associated with reduced survival in all groups.
\end{abstract}

\section{Hosted file}

AVRppm ATS 05072020 revised2.doc available at https://authorea.com/users/350217/articles/ 475106-impact-of-valve-size-effective-and-indexed-effective-orifice-area-after-aorticvalve-replacement

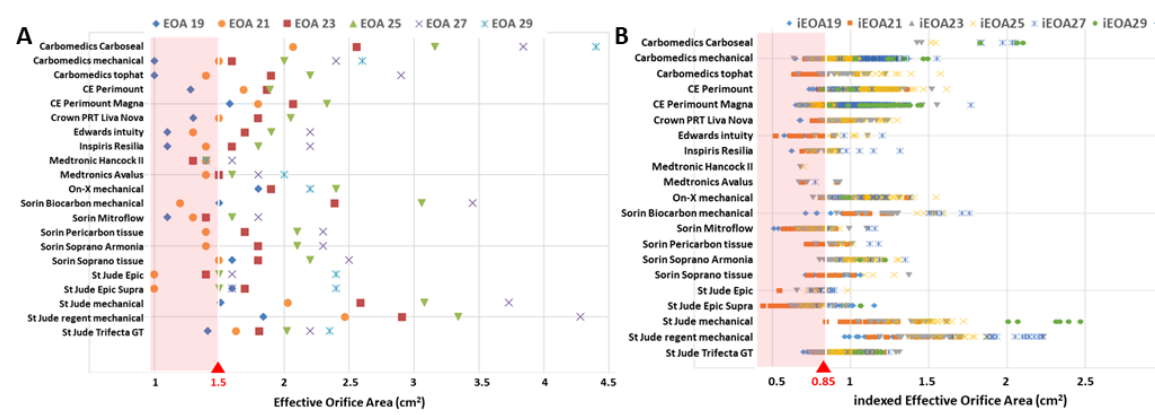



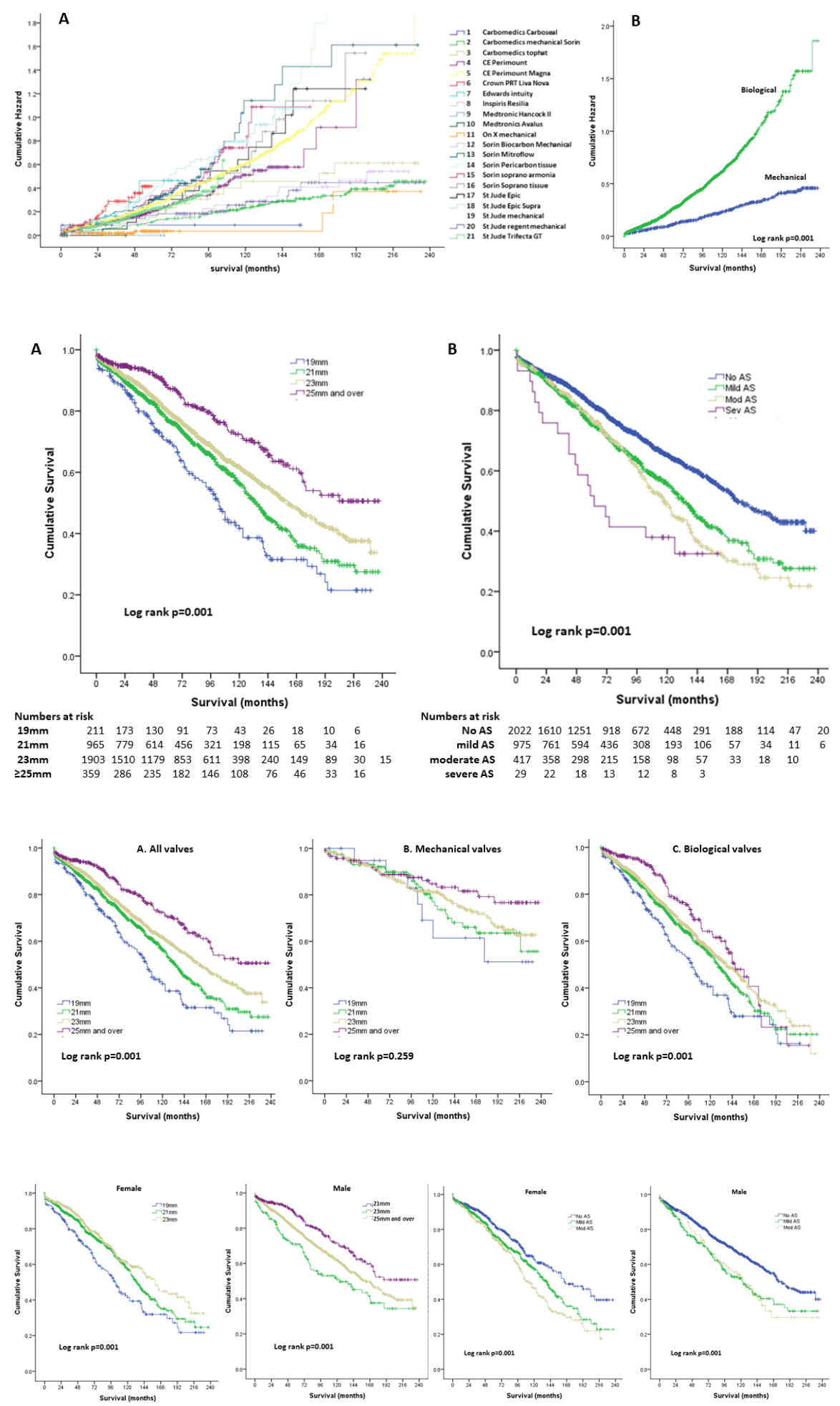


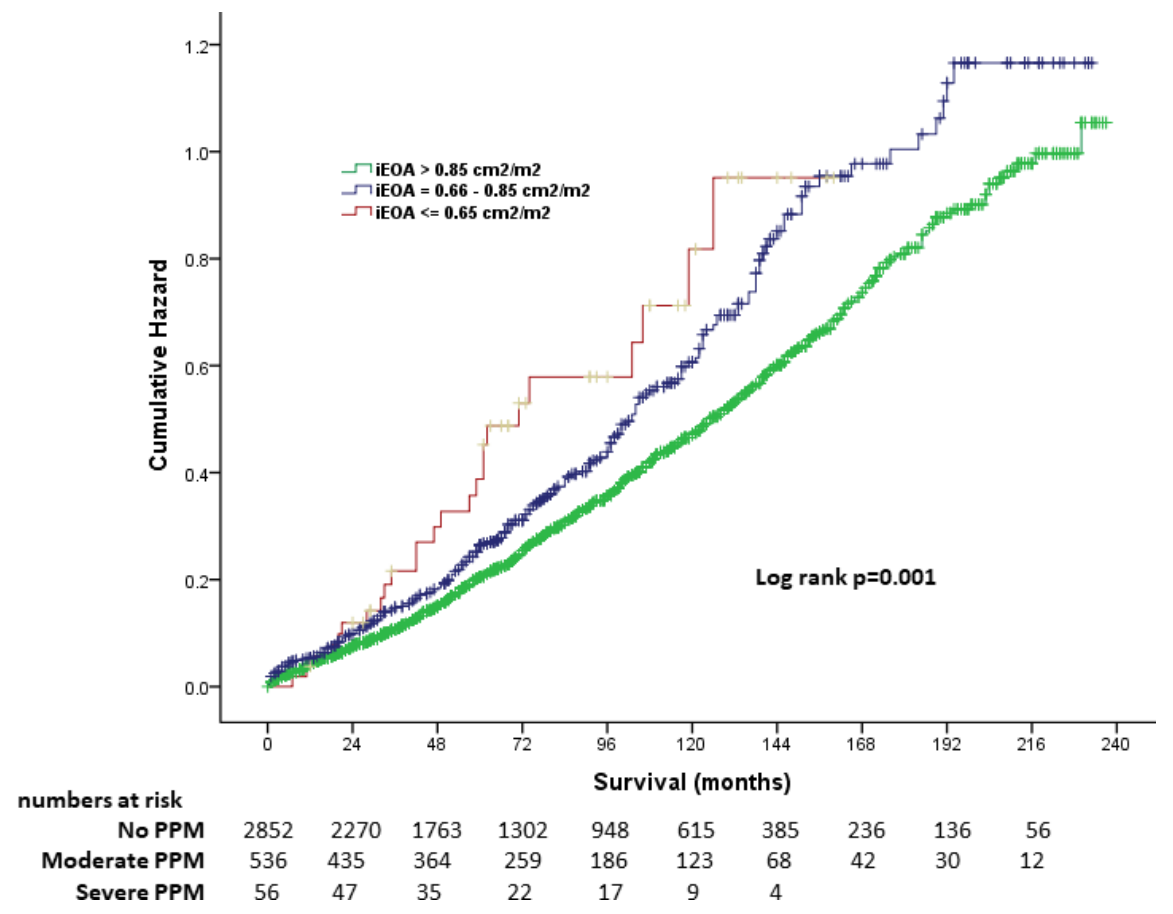

\section{Hosted file}

tables.doc available at https://authorea.com/users/350217/articles/475106-impact-of-valvesize-effective-and-indexed-effective-orifice-area-after-aortic-valve-replacement 